Check for updates

Cite this: RSC Adv., 2017, 7, 32468

\title{
Engineering prevascularized composite cell sheet by light-induced cell sheet technology
}

\author{
Ying Zhou, $\dagger^{a}$ Lingqing Dong, (ID $\dagger^{\mathrm{ab}}$ Chao Liu, ${ }^{a}$ Yihan Lin, ${ }^{a}$ Mengfei Yu, (D) *ac Liang Ma, ${ }^{d}$ \\ Bin Zhang, ${ }^{d}$ Kui Cheng, ${ }^{b}$ Wenjian Weng ${ }^{D}{ }^{b}$ and Huiming Wang ${ }^{\star a c}$
}

Early vascularization in bone defects has been considered to play a critical role in the bone regeneration process. Although mesenchymal stem cells (MSCs) co-cultured with endothelial cells (ECs) have attracted the most attention in strategies that seek to achieve vascularized bone, it still remains a challenge to achieve a prevascularized construct in vitro that can be translated conveniently. Here, we provided a strategy of engineering a transferable prevascularized MSC-EC composite cell sheet to promote the vascular-like network formation for bone tissue engineering. We co-cultured human mesenchymal stem cells (hMSCs) and human umbilical vein endothelial cells (HUVECs) on a distinct light-responsive $\mathrm{TiO}_{2}$ nanodots film. Various cell ratios of MSC-EC and culture mediums were explored to achieve the optimal angiogenesis capacity. The prevascularized MSC-EC composite cell sheet was then detached as an intact and confluent cell layer by a simple light treatment, and showed high viability and 3D network formation surrounded by mesenchymal stem cells. This light-induced cell sheet technology therefore realized a novel transferable prevascularized MSC-EC composite cell sheet, and will have a profound impact on further strategies for designing in-bone tissue engineering.

Received 11th May 2017

Accepted 19th June 2017

DOI: 10.1039/c7ra05333a

rsc.li/rsc-advances the success of vascularization in implanted engineered constructs.

Cell sheet engineering, leading to cell recovery in an intact layer of confluent cells, has emerged as a useful strategy in regenerative medicine. ${ }^{5}$ Different from dissociated cells, cell sheets preserve cell junctions and intact extracellular matrix (ECM) that provides signals to control the morphology, structure and function of tissue and organs. ${ }^{6}$ Previous studies have demonstrated the use of cell sheet for the regeneration of myocardium, cornea and periodontal ligaments. ${ }^{7-9}$ Therefore, we speculate that the layered cell sheet consisting of MSCs and ECs formed in vitro might preserve the vascular-like structures and be used directly or in combination with scaffolds for bone tissue engineering. Several studies have investigated the addition of ECs in cell sheets for bone tissue engineering. In most studies, MSCs were seeded on a cell culture dish to form a cell sheet. Then, ECs were seeded on the surface of the MSC cell sheet in 4 days of culture for transplantation. ${ }^{\mathbf{1 0 , 1 1}}$ However, few studies have concentrated on the mixed seeding of MSCs and ECs for co-culture to generate prevascularized cell sheet. Since co-cultured cell sheet will make a better combination and cell-cell junction of two kinds of cells, coculture for prolonged periods might generate a stable and mature vascular network in vitro for better vascularization in vivo.

Recently, we have developed a novel cell sheet technology based on a light-responsive $\mathrm{TiO}_{2}$ nanodots film. ${ }^{12}$ An intact and confluent cell layer could be detached easily due to the 
generation of distinct surface hydroxyl groups triggered by a simply light treatment. However, these previous efforts have only reported the detachment of mono-cultured cell sheets. The design of co-cultured composite cell sheet as well as engineering the distinct culture conditions, such as cell ratio and media, still need to be explored.

In this study, we aimed to provide a transferable cocultured MSC-EC composite cell sheet to promote the formation of vascular-like network for bone tissue engineering. We co-cultured hMSCs and HUVECs on lightresponsive $\mathrm{TiO}_{2}$ nanodots film at various cell ratio and media. The vessel-like structures, cell metabolic activity and osteogenic potential of the co-cultured MSC-EC cell sheet were systematic evaluated to identify the optimal prevascularized composite cell sheet with high viability and 3D network formation for bone regeneration.

\section{Materials and methods}

\section{Preparation of $\mathrm{TiO}_{2}$ nanodots film}

$\mathrm{TiO}_{2}$ nanodots film (TN) was prepared on a silicon substrate through phase separation-induced self-assembly as we described previously. ${ }^{12}$ Briefly, a precursor sol containing titanium tetrabutoxide (TBOT, Sinopharm Chemical Reagent, CP, >98\%), acetylacetone (AcAc, Lingfeng Chemical Reagent, AR, >99\%) and polyvinyl pyrrolidone (PVP, K30, Sinopharm Chemical Reagent, $\mathrm{AR},>99 \%$ ), was spin-coated on substrate and allowed for phaseseparate after further heat treated at $500{ }^{\circ} \mathrm{C}$. A $\mathrm{TiO}_{2}$ nanodots film was then obtained as light-responsive culture surface and characterized by scanning electron microscope (Hitachi, Su-70) and transmission electron microscopy (FEI, F-20).

\section{Cell culture}

Human mesenchymal stem cells were obtained from iliac crest marrow aspirates collected from healthy donors for iliac crest bone transplantation at The First Affiliated Hospital of College of Medicine, Zhejiang University (China). All the samples were obtained with informed consent. This procedure was performed following approval from the Institutional Review Board of First Affiliated Hospital, College of Medicine, Zhejiang University. The reference number of this study is 2016294. The study was conducted in accordance with Regulations on Research of Medical Science and Technology Involving the Human Body. These regulations are formulated by National Health and Family Planning Commission of the People's Republic of China.

Mononuclear cells (MNCs) were separated according to previous studies. ${ }^{13}$ In brief, hMSCs were isolated by densitygradient centrifugation over Histopaque®-1077 (SigmaAldrich, St. Louis, MO, USA) and expanded in DMEM medium (Gibco) supplemented with 10\% FBS (Gibco).

Primary human umbilical vein endothelial cells were purchased from ATCC (Rockville, MD, USA). Cells were cultured in VCM medium (ATCC $®$ ) that consisted of endothelial cell basal medium and a growth kit of supplements.

\section{Co-culture of hMSCs with HUVECs}

hMSCs and HUVECs were trypsinized by trypsin-EDTA (Gibco) separately and co-cultured on light sensitive culture surface at different cell ratio in various media. The cell ratio of hMSCs versus HUVECs included $100: 0,90: 10,75: 25,50: 50$ and the cell density was 10000 cells per $\mathrm{cm}^{2}$ on $\mathrm{TiO}_{2}$ nanodots surface in 24-well plates. The content of the various media was listed in Table 1 . The culture medium was changed every other day. Cell morphology was observed by an inverted light microscopy (Olympus, Tokyo, Japan).

\section{Cell sheet detachment}

The detachment of cell sheet from $\mathrm{TiO}_{2}$ nanodots film was performed using a cold LED UV light. The wavelength of the UV light was $365 \mathrm{~nm}$ and the power was set as $2.0 \mathrm{~mW} \mathrm{~cm}^{-2}$. Cells co-cultured on $\mathrm{TiO}_{2}$ nanodots film were washed with PBS for three times, followed by UV365 illumination for $20 \mathrm{~min}$. The transmittance power was $1.4 \mathrm{~mW} \mathrm{~cm}^{-2}$.

\section{Immunofluorescent assay}

Immunofluorescence of endothelial cell marker rhodamine labeled UEA I (Vector Laboratories, Burlingame, CA) or CD31 (DakoCytomation, Copenhagen, Denmark) was performed to visualize the vascular-like formation of HUVECs in cell sheet. Briefly, cells were fixed with $4 \%$ paraformaldehyde for $15 \mathrm{~min}$ after rinsed with PBS. Then, cells were stained with rhodamine UEA I lectin or with primary antibody CD31 followed by an Alexa Fluor ${ }^{\circledR}-488$ conjugated secondary antibody (Molecular Probes Inc). Nucleus was stained using DAPI (Molecular Probe ${ }^{\mathrm{TM}}, \mathrm{UK}$ ). The cell cytoskeleton was labeled red with rhodamine phalloidin after cell sheet detachment (Cytoskeleton, Denver, USA). Finally, the samples were mounted and studied by fluorescence

Table 1 The content of various media for growth of composite cell sheet

\begin{tabular}{|c|c|c|}
\hline \multicolumn{2}{|l|}{ Medium name } & \multirow{2}{*}{$\begin{array}{l}\text { Content } \\
\text { H-DMEM (Gibco), 10\% FBS (Gibco) }\end{array}$} \\
\hline Mesenchymal & $\mathrm{H}$ & \\
\hline stem cells & $\mathrm{L}$ & L-DMEM (Gibco), 10\% FBS (Gibco) \\
\hline growth media & $\alpha$ & $\alpha$-MEM (Gibco), 10\% FBS (Gibco) \\
\hline \multirow[t]{3}{*}{ Mixed media } & $\mathrm{H}-\mathrm{V}$ & $\begin{array}{l}50 \% \mathrm{H} \text { medium and 50\% VCM } \\
\text { medium (ATCC) }\end{array}$ \\
\hline & $\mathrm{L}-\mathrm{V}$ & $\begin{array}{l}50 \% \mathrm{~L} \text { medium and 50\% VCM } \\
\text { medium (ATCC) }\end{array}$ \\
\hline & $\alpha-\mathrm{V}$ & $\begin{array}{l}50 \% \alpha \text { medium and } 50 \% \text { VCM } \\
\text { medium (ATCC) }\end{array}$ \\
\hline Osteogenic & H-osteo & $\mathrm{H}$ medium and osteogenic factors \\
\hline growth media & $\begin{array}{l}\mathrm{L} \text {-osteo } \\
\alpha \text {-osteo }\end{array}$ & $\begin{array}{l}\mathrm{L} \text { medium and osteogenic factors } \\
\alpha \text { medium and osteogenic factors }\end{array}$ \\
\hline Osteogenic & $\mathrm{H}-\mathrm{V}-\mathrm{osteo}$ & $\mathrm{H}-\mathrm{V}$ medium and osteogenic factors \\
\hline mixed media & $\begin{array}{l}\mathrm{L}-\mathrm{V} \text {-osteo } \\
\alpha-\mathrm{V} \text {-osteo }\end{array}$ & $\begin{array}{l}\mathrm{L}-\mathrm{V} \text { medium and osteogenic factors } \\
\alpha-\mathrm{V} \text { medium and osteogenic factors }\end{array}$ \\
\hline $\begin{array}{l}\text { Supplements: } \\
\text { osteogenic } \\
\text { factors }\end{array}$ & Osteo & $\begin{array}{l}50 \mu \mathrm{M} \text { ascorbic acid (Sigma) } \\
100 \mathrm{nM} \text { dexamethasone (Sigma) } \\
10 \mathrm{mM} \beta \text {-glycerophosphate (Sigma) }\end{array}$ \\
\hline
\end{tabular}


(a)

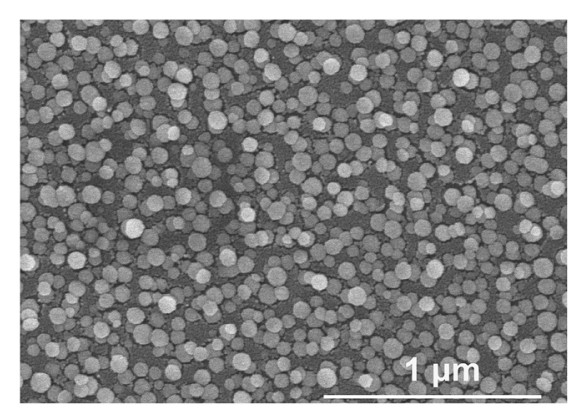

(c)

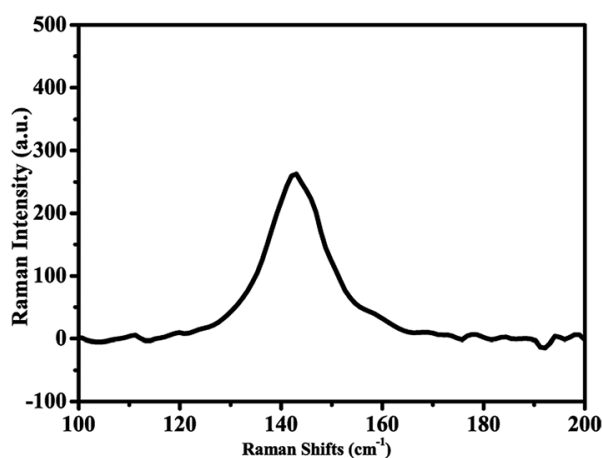

(b)
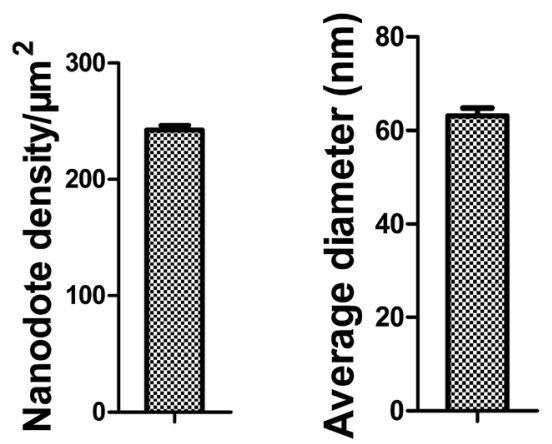

(d)

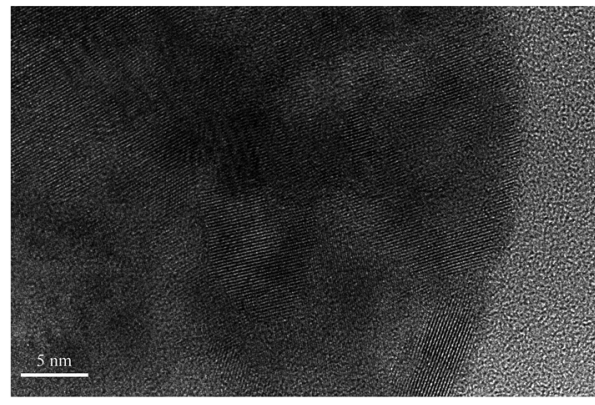

Fig. 1 Characterization of light-responsive $\mathrm{TiO}_{2}$ nanodots film. (a) SEM image of the $\mathrm{TiO}_{2}$ nanodots film and statistical analysis of the density and average diameter (b) of the nanodots. (c) The corresponding Raman spectra. (d) High resolution transmission electron microscopy (TEM) image of a typical nanodot.

microscopy (Zeiss, Oberkochen, Germany). The total capillarylike length and the average length of branches were quantified using Image J software (NIH).

\section{Cell metabolic activity}

AlamarBlue assay (Invitrogen) was performed to measure cell metabolic activity. After culturing on light sensitive culture

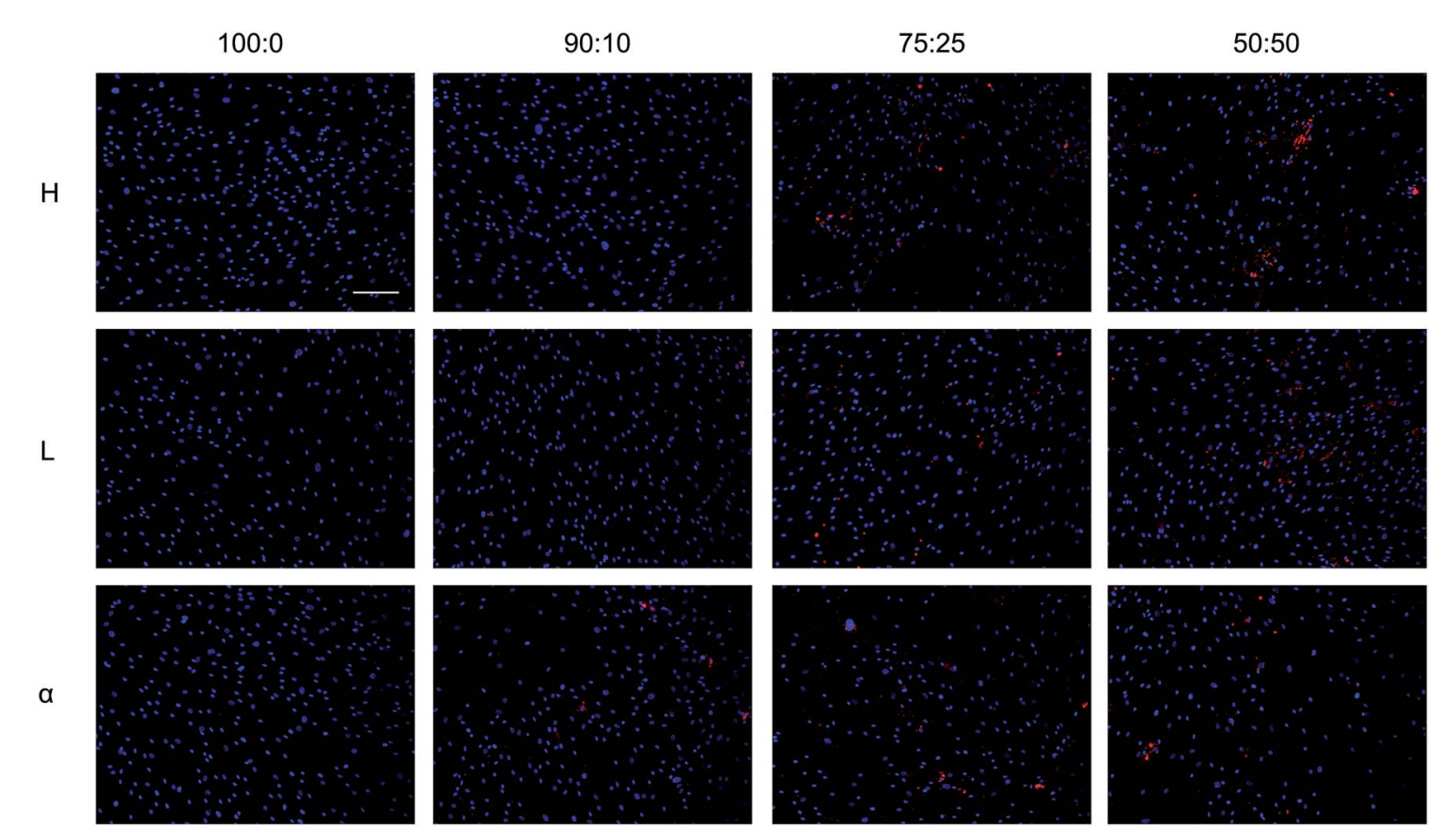

Fig. 2 Effect of pure MSC growth media on HUVECs growth in composite cell sheets. Immunofluorescent assay of UEA I indicated that HUVECs could not survive in pure MSC growth media including $\mathrm{H}$ medium, L medium and $\alpha$ medium after 7 days of culture. Scale bars, $200 \mu \mathrm{m}$. 
surface for $24 \mathrm{~h}, 48 \mathrm{~h}$ and $72 \mathrm{~h}$, the medium in each well was removed and replaced with $500 \mu$ l AlamarBlue solution, which consisted of $50 \mu \mathrm{l}$ AlamarBlue and $450 \mu \mathrm{l}$ fresh culture medium. Then the plates were incubated for 2 hours in a humidified atmosphere of $5 \% \mathrm{CO}_{2}$ at $37{ }^{\circ} \mathrm{C}$. Finally, $300 \mu \mathrm{l}$ AlamarBlue solution derived from each well was aspirated and added to 96-well plates for fluorescence analysis as three duplicates. The resulting fluorescence was evaluated using excitation wavelength of $540 \mathrm{~nm}$ and emission wavelength of 590 on a microplate reader SpectraMax i3 (Molecular Devices, Sunnyvale, USA).

\section{Alkaline phosphatase (ALP) activity}

ALP LabAssay Kit (Wako, Japan) was used to evaluate the ALP activity, following the manufacturer's instructions. Briefly, supernatant from different ratio of culture groups were harvested as samples. Standard protein was diluted in series to measure the standard curve. A substrate tablet was dissolved into $5 \mathrm{ml}$ of buffer solution to generate working assay solution. Then, $100 \mu \mathrm{l}$ working assay solution was added into $20 \mu \mathrm{l}$ sample or standard protein in 96-well plates. Three duplicates of each sample were performed. After incubation at $37{ }^{\circ} \mathrm{C}$ for 15 minutes, $80 \mu \mathrm{l}$ stop solution was added to stop the reaction. Finally, shaked the plate for 1 minute and measured the absorbance at $405 \mathrm{~nm}$ of wavelength using microplate reader SpectraMax i3 (Molecular Devices, Sunnyvale, USA).

\section{Live-dead staining assay}

The detached cell sheet viability after UV illumination was assessed using LIVE/DEAD® viability/cytotoxicity kit (a)
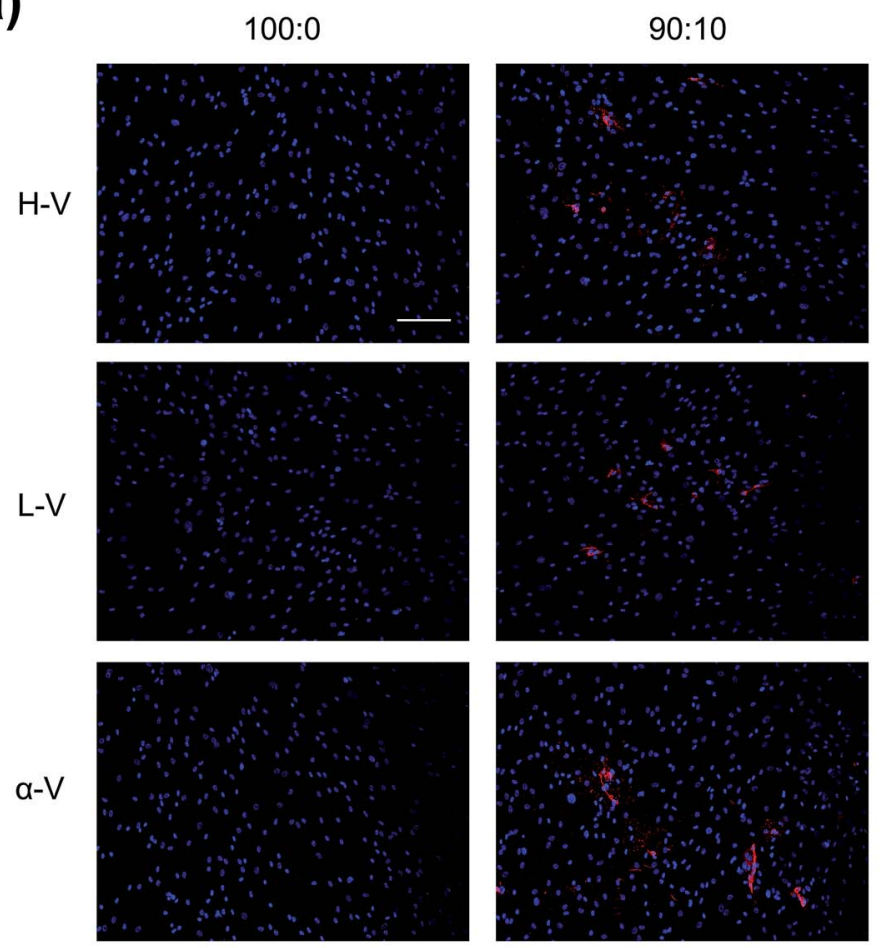

$75: 25$
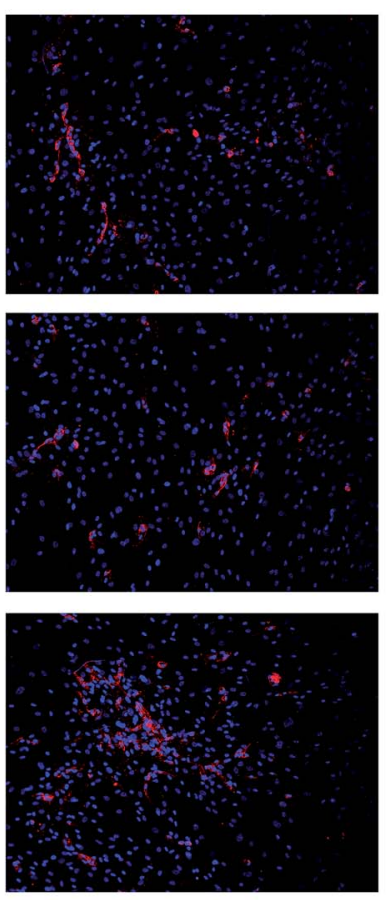

$50: 50$
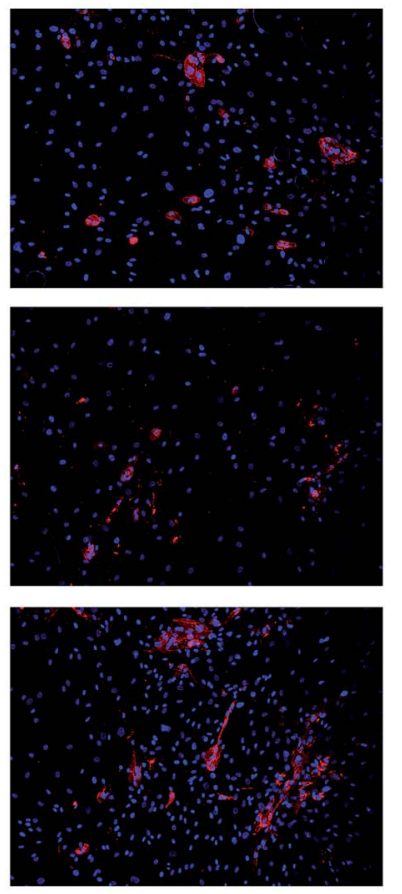

(b)
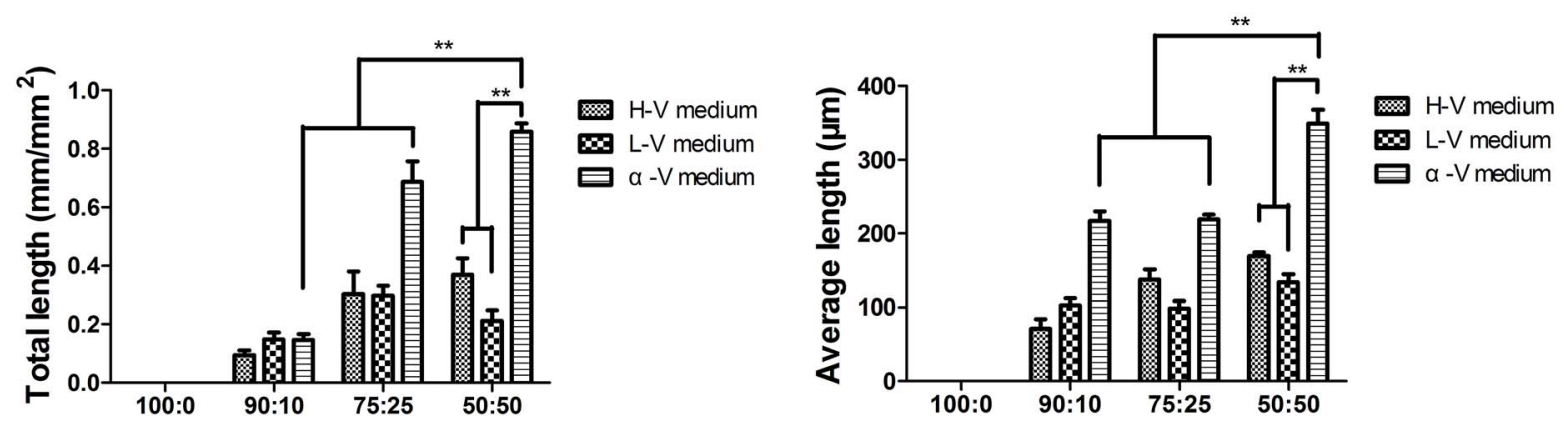

Fig. 3 Effect of mixed media on HUVECs distribution in composite cell sheets. (a) Immunofluorescence indicated that HUVECs distribution increased with endothelial cell ratio in mixed media $(50: 50>75: 25>90: 10)$. HUVECs in $\alpha-V$ medium appeared as tube-like morphology and displayed more extensive distribution in co-culture than that in $\mathrm{H}-\mathrm{V}$ and $\mathrm{L}-\mathrm{V}$ media at the same ratio. (b) Quantitative analysis showed the highest total length and average length of tube-like structures in $50: 50$ group under $\alpha-V$ medium. Results are shown as the average values \pm SD. Significance levels were set at: *: $p<0.05, * *: p<0.01$. Scale bars, $200 \mu \mathrm{m}$. 
(Invitrogen), in which calcein AM and ethidium homodimer-1 were used to determine the living and dead cells respectively. Briefly, a mixed solution of calcein AM and ethidium homodimer-1 was prepared and added to cell sheets for incubation at room temperature for $30 \mathrm{~min}$. Cell sheets were then studied by a fluorescence microscopy (Zeiss, Oberkochen, Germany).

\section{Statistical analysis}

All data were expressed as mean \pm standard deviation (SD) for three independent experiments. One-way analysis of variance (ANOVA) was used to test for significance using the GraphPad Prism Version 5.0 (GraphPad, San Diego, CA, US) and SPSS Statistics 18.0 (IBM, Armonk, NY, US). Differences were considered statistically significant at $p<0.05$.

\section{Results}

\section{Characterization of $\mathrm{TiO}_{2}$ nanodots film}

The $\mathrm{TiO}_{2}$ nanodots film obtained after $500{ }^{\circ} \mathrm{C}$ heating was characterized by scanning electron microscope (SEM) and transmission electron microscopy (TEM). As shown in Fig. 1a, the SEM image showed homogeneous distribution of the $\mathrm{TiO}_{2}$ nanodots. The density and average diameter of the nanodots were $242 \mu \mathrm{m}^{-2}$ and $63 \mathrm{~nm}$, respectively (Fig. 1b). Furthermore, the Raman spectra was used to analyze the phase of $\mathrm{TiO}_{2}$ nanodots. As shown in Fig. 1c, the band located at $144 \mathrm{~cm}^{-1}$ was indexed to the Raman active modes $\mathrm{E}_{\mathrm{g}}$ of anatase $\mathrm{TiO}_{2}$. Moreover, the high resolution TEM image of a typical nanodot clearly showed that the nanodots are polycrystalline (Fig. 1d). These results were consistent with our previous work. ${ }^{\mathbf{1 4 , 1 5}}$

\section{Effects of various culture media and cell ratio on network formation in cell sheets}

To achieve the prevascularized cell sheet on light-responsive $\mathrm{TiO}_{2}$ nanodots film, different cell ratio of HUVECs/hMSCs were cultured in various media to identify the optimal conditions for co-cultures (Table 1). Immunofluorescent assay of UEA I was carried out to characterize the distribution of HUVECs in cell sheets. Specifically, HUVECs were not present within the cocultures neither in $\mathrm{H}$ medium, L medium nor $\alpha$ medium after 7 days of culture (Fig. 2), indicating that HUVECs could not survive in pure growth media of mesenchymal stem cells. In contrast, HUVECs co-cultured in mixed media $(\mathrm{H}-\mathrm{V}$ medium, $\mathrm{L}-\mathrm{V}$ medium, $\alpha-\mathrm{V}$ medium) dispersedly distributed among hMSCs on day 7 (Fig. 3a). It was notable that the fluorescence of UEA I enhanced with the increase of the cell ratio of HUVECs in co-culture $(50: 50>75: 25>90: 10)$. And HUVECs in $\alpha-\mathrm{V}$ medium displayed more extensive distribution in co-culture than that in $\mathrm{H}-\mathrm{V}$ and $\mathrm{L}-\mathrm{V}$ media at the same ratio. In the cell ratio of $50: 50$ group under $\alpha-\mathrm{V}$ medium, the adjacent ECs gathered together, turned into elongated shape and organized into tube-like structures. Quantitative analysis showed that total length and average length of tube-like structures of cells cultured in $50: 50$ ratio under $\alpha-\mathrm{V}$ medium group represented significantly higher than that of other groups (Fig. 3b).

In order to promote the perivascular differentiation of hMSCs in cell sheet, osteogenic factors were added into the 6 media

\section{Day3}
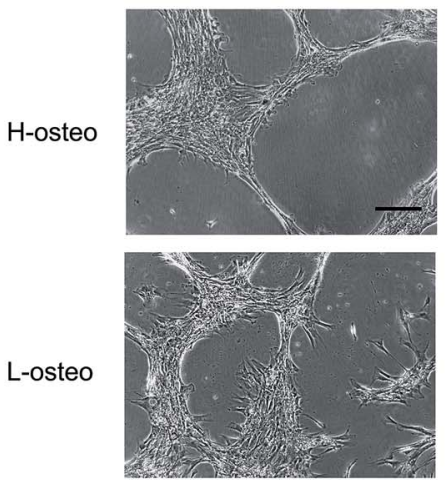

L-osteo

\section{Day7}

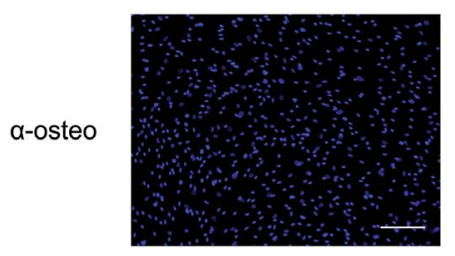

$90: 10$
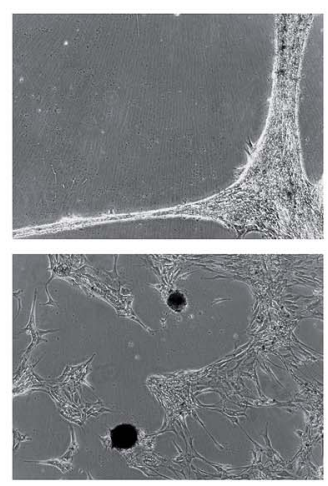

$90: 10$

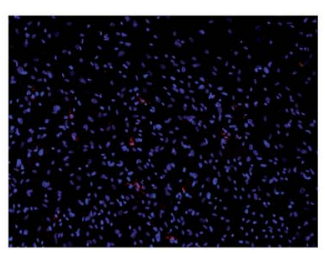

$75: 25$
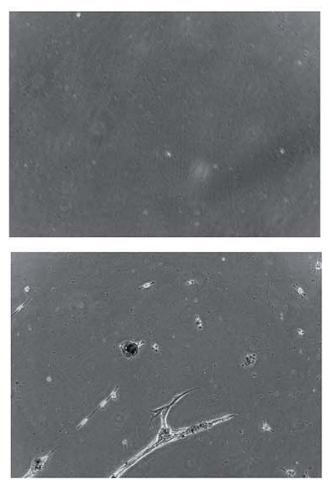

$75: 25$

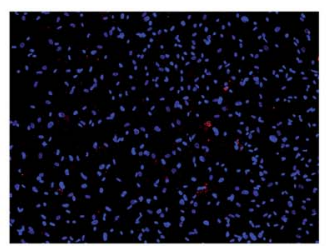

$50: 50$

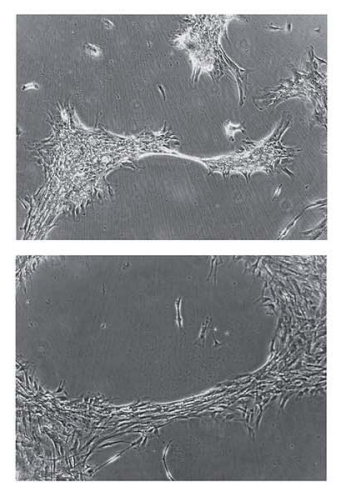

$50: 50$

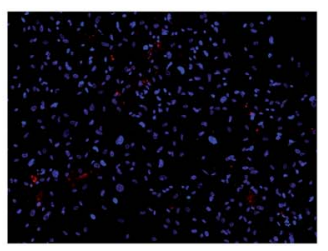

Fig. 4 Effect of osteogenic growth media on HUVECs distribution in composite cell sheets. Cells detached spontaneous from light sensitive culture surface after 3 days of culture in $\mathrm{H}$-osteo medium and L-osteo medium, while cells in $\alpha$-osteo medium could grow for 7 days but with no HUVECs survival in this medium. Scale bars, $200 \mu \mathrm{m}$. 
(a)

(b)
100:0
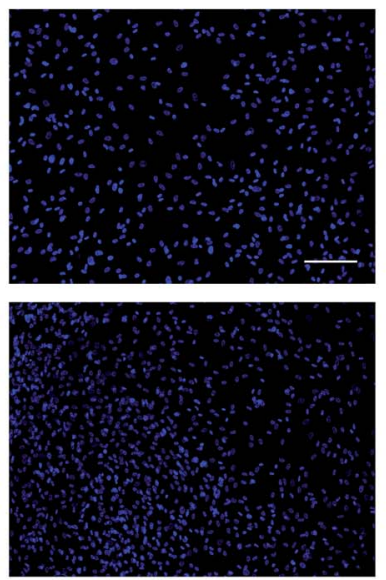

L-V-osteo

$\alpha-\mathrm{V}$-osteo

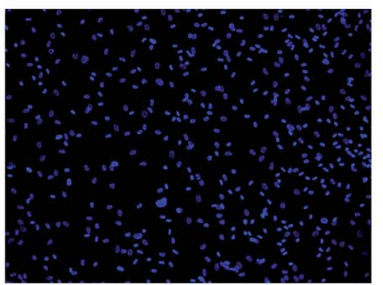

90:10
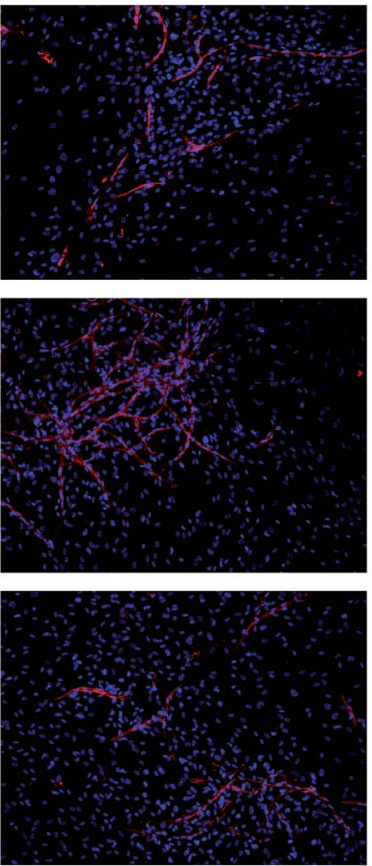

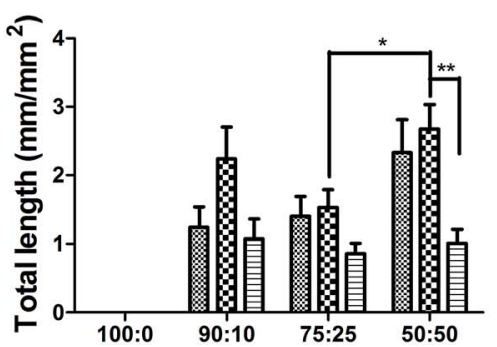

m-V-osteo medium $\infty$ L-V-osteo medium $\square \alpha-V$-osteo medium

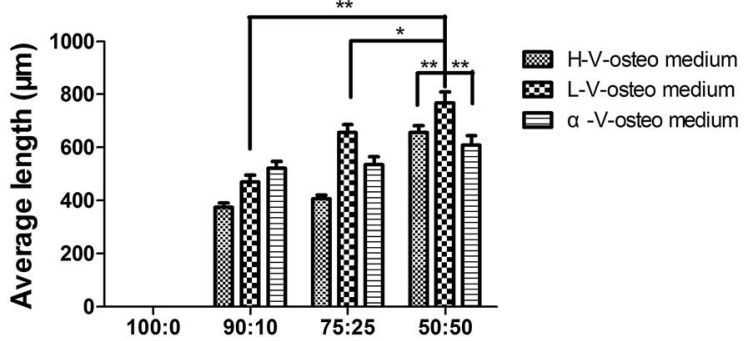

Fig. 5 Effect of mixed osteogenic media on network formation in composite cell sheets. (a) HUVECs in cell sheet proliferated dramatically after addition of osteogenic factors and rearranged into vascular-like network especially in $L-V$-osteo medium. The network formation in 50 : 50 group under $\mathrm{L}-\mathrm{V}$-osteo medium appeared into interconnected and branched morphology with large diameter compared with that in other groups. (b) Quantitative analysis of vascular-like network showed an increase of both total network length and average branch length in 50 : 50 group under $\mathrm{L}-\mathrm{V}$-osteo medium. Results are shown as the average values $\pm \mathrm{SD}$. Significance levels were set at: *: $p<0.05, * *: p<0.01$. Scale bars, $200 \mu \mathrm{m}$.

above for 7 days of co-culture. Interestingly, after 3 days of culture in $\mathrm{H}$-osteo medium and $\mathrm{L}$-osteo medium, a number of cells detached spontaneously from light-responsive $\mathrm{TiO}_{2}$ nanodots film, while cells cultured in $\alpha$-osteo medium could grow for 7 days but with no HUVECs (Fig. 4). In contrast, under osteogenic mixed media, HUVECs proliferated dramatically after the stimulation of osteogenic factors, especially in L-V-osteo medium (Fig. 5a). Meanwhile, in $\mathrm{L}-\mathrm{V}-$-osteo medium, HUVECs in $50: 50$ group proliferated obviously and numerous ECs organized into vascular-like network with large diameter, whereas cells in $75: 25$ group displayed in thick tube-like structure with fewer branches. However, HUVECs in 90:10 group were observed to form predominantly of a single elongated cell layer and organize into capillary-like structures of much smaller diameters (Fig. 5a). Furthermore, quantitative analysis of vascular-like network also showed that both total network length and average branch length were up-regulated in 50:50 group under L-V-osteo medium compared with other groups (Fig. 5b).

\section{Screen of the optimal culture system for prevascularized composite cell sheet}

Based on the analysis above, we proposed that $\mathrm{L}-\mathrm{V}-\mathrm{osteo}$ medium might be the optimal medium for the construction of prevascularized cell sheet. To further confirm the hypothesis and identify the optimal cell ratio, different cell ratio of hMSCs and HUVECs were co-cultured in L-V-osteo medium on lightresponsive $\mathrm{TiO}_{2}$ nanodots film. After 7 days of culture, immunofluorescence staining of CD31 was performed to visualize the network formation among different groups. As shown in Fig. 6a, HUVECs in 50:50 group interconnected and rearranged into more extensive vascular-like network with thick branches compared to that of cells in $75: 25$ group. Nevertheless, HUVECs co-cultured in $90: 10$ group appeared to be elongated and cord-like structure with few branches.

Cell metabolic activity of cell sheet was then assessed by AlamarBlue assay among different ratio of groups at selective 
(a)

time point. As shown in Fig. 6b, metabolic activity of cells sheet increased from day 1 to day 3, and 50:50 group displayed higher metabolic activity than the other two groups at the same time point $(75: 25,90: 10)$, while the $90: 10$ group displayed the lowest metabolic activity. These data indicated the highest cell proliferation and viability in $50: 50$ group.

To further explore the osteogenic differentiation of composite cell sheet, ALP activity evaluation was carried out on day 1 , day 3 and day 5. It was notable in Fig. 6c that ALP activity was up-regulated with the increased ratio of HUVECs, showing that co-cultures displayed higher ALP activity than the monoculture of hMSCs. It was found that cell ratio in $50: 50$ group achieved the highest ALP activity among all groups.

\section{Characterization of optimal light-induced cell sheet after detachment}

After identifying the best culture conditions for prevascularized composite cell sheet, we further characterized the properties of the optimal cell sheet after detachment. As shown in Fig. 7a, the detached cell sheet exhibited as an intact and translucent membrane. Live-dead staining assay revealed that almost all cells survived with good viability in cell sheet after detachment (Fig. 7b), indicating that there was no significant difference of cell growth before and after light triggering. Meanwhile, immunofluorescence indicated that HUVECs organized into 3D networks and were surrounded by numerous hMSCs in horizontal and vertical directions (Fig. 7c). These results demonstrated the successful harvest of a viable and prevascularized composite cell sheet using our light-induced cell sheet technology.

\section{Discussion}

Bone formation is a complex process involving calcified matrix deposition and vascular formation, while insufficient vascularization inside the engineered construct has been a significant factor hampers its implanted survival. Therefore, rapid and sufficient formation of vascular network is a big challenge in bone regeneration, especially in large bone reconstruction. One way to overcome this challenge is to generate prevascularized constructs using osteogenic and angiogenic cells by mimicking the natural environment in vivo. ${ }^{\mathbf{1 6}}$ The main objective of the present study was to create a prevascularized cell sheet combining mesenchymal stem cells and endothelial cells based on cell sheet technology.

Recently, we have reported the development of a novel lightinduced cell sheet technology based on a light-sensitive $\mathrm{TiO}_{2}$ nanodots film. ${ }^{12}$ This $\mathrm{TiO}_{2}$ nanodots film was prepared through phase separation induced self-assembly, with the dot diameter ranged from 30 to $110 \mathrm{~nm}$. The nanodots obtained were polycrystalline (Fig. 1c and d). During cell cultivation, proteins from the culture medium adsorbed rapidly on the surface of $\mathrm{TiO}_{2}$ nanodots and then mediated the adhesion of cells. After UV illuminated, the hydroxyl groups on the surface of $\mathrm{TiO}_{2}$ nanodots were increasing, which would stimulate the protein to change its conformation and release from the $\mathrm{TiO}_{2}$ nanodots, making the confluent cell layer detached from the TN film. ${ }^{12}$ As a strategy to fabricate prevascularized construct, one of its significances falls on the determination of the ideal in vitro culture conditions that facilitate the robust vascular-like networks formation. In the present study, we generated 
(a)

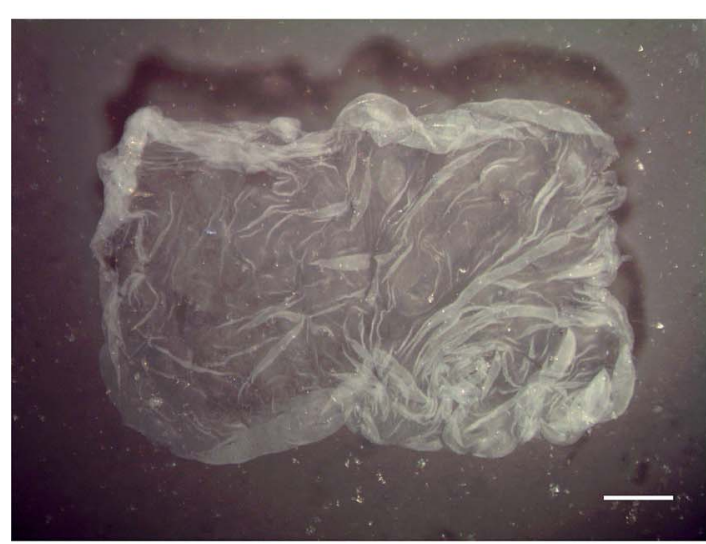

(b)
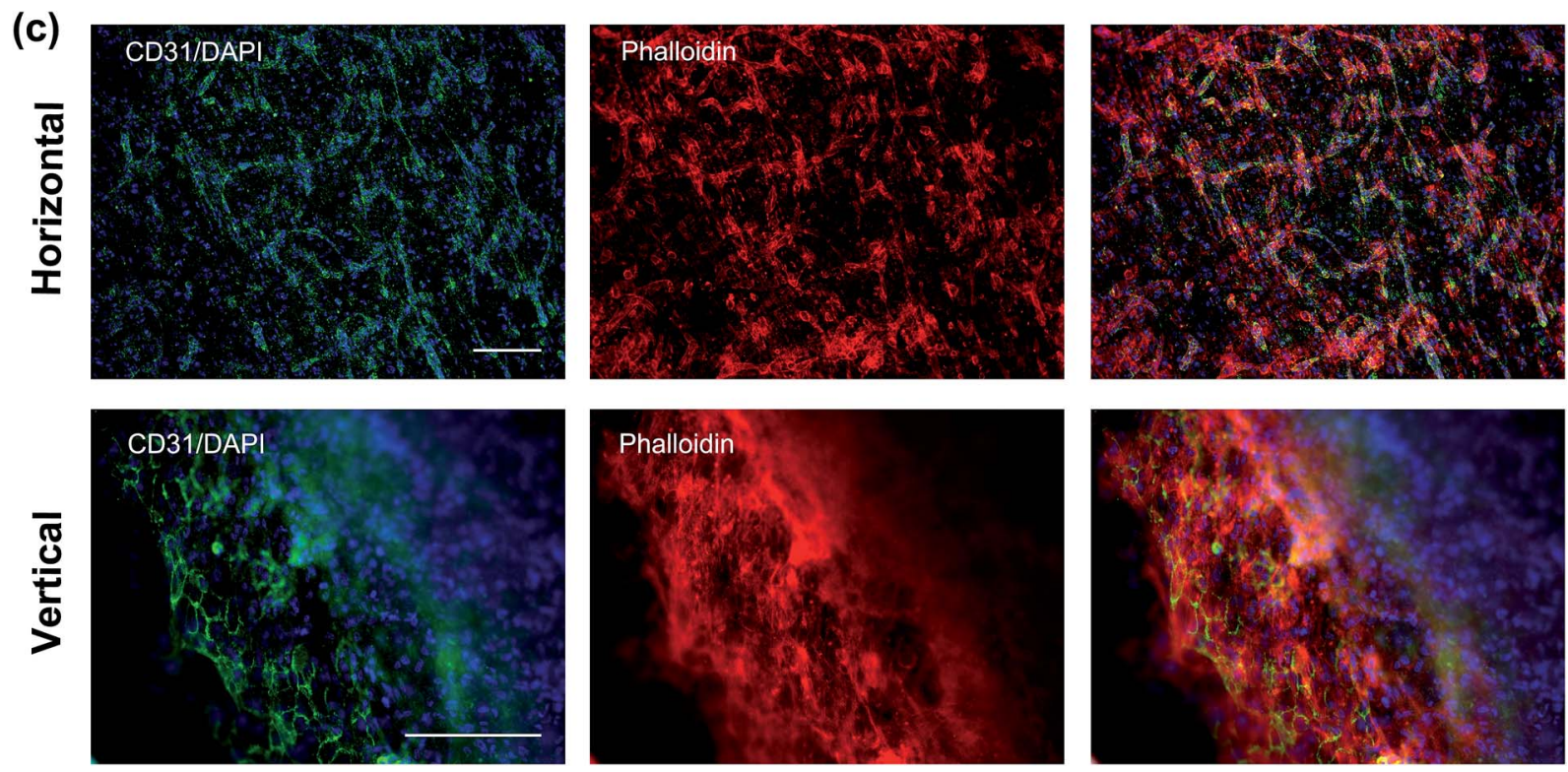

Fig. 7 Characterization of optimal light-induced cell sheet after detachment. (a) Macroscopic observation of the optimal prevascularized composite cell sheet after light-induced detachment. Scale bars, $1 \mathrm{~mm}$. (b) Live-dead staining assay revealed that almost all cells survived in cell sheet after detachment. Live cells were stained with calcein (green), and dead cells were stained with ethidium homodimer (red). Scale bars, 200 $\mu \mathrm{m}$. (c) Immunofluorescence of CD31 (green) and phalloidin (red) showed that HUVECs organized into 3D networks and were surrounded by numerous hMSCs in horizontal and vertical directions. Scale bars, $200 \mu \mathrm{m}$.

various MSC-EC composite cell sheets in various culture media and cell ratio. We found that HUVECs could survive in mixed media ( $\mathrm{H}-\mathrm{V}$ medium, $\mathrm{L}-\mathrm{V}$ medium, $\alpha-\mathrm{V}$ medium) and formed into tube like structures (Fig. 3), but couldn't survive in pure MSCs growth media (H medium, L medium, $\alpha$ medium) in cell sheets (Fig. 2). These results suggested that some growth factors contained in mixed media might promote the growth of HUVECs in cell sheets. However, HUVECs co-cultured in osteogenic mixed media proliferated dramatically and organized into prevascularized cell sheets (Fig. 5 and 6a). The formation of vascular-like network might be stimulated by the osteogenic factors, since several studies have also described the role of osteogenic medium on vascularization. ${ }^{17,18}$

After identifying the best culture medium for the vascularlike network formation, we then focused on the optimal cell ratio of hMSCs and HUVECs in the composite cell sheet. As different cell ratios exerted different effects on angiogenesis and osteogenesis in co-culture system, results have been conflicting. Some studies demonstrated that low percentages of HUVECs stimulated the formation of the vascular network and upregulated the expression of alkaline phosphatase. ${ }^{18,19}$ Nevertheless, others showed that 50\% ECs combined with 50\% MSCs resulted in the highest proliferation and ALP activity in culture plates. $^{20,21}$ In this study, we evaluated the cell metabolic activity and ALP activity in cell sheets using different cell ratio, and found $50: 50$ group presented the highest cell proliferation and osteogenic ability. Moreover, HUVECs in $50: 50$ group organized into more extensive vascular-like network with thick branches than other groups during cell sheet culture (Fig. 5 and 6a). These networks with long vascular-like structures and thick branches would minimize the distance between host ECs and capillaries, and thereby accelerating functional anastomosis after transplantation. These results implied that $\mathrm{L}-\mathrm{V}-\mathrm{osteo}$ medium combined with $50: 50$ cell ratio were the optimal 
culture conditions for the construction of prevascularized composite cell sheet.

The coincidence of more pronounced networks formation and higher ALP activity was found in 50:50 group suggested the close connection between the two processes of angiogenesis and osteogenesis. Actually, during bone development, MSCs and ECs interact with each other to promote bone generation. ${ }^{22,23}$ Previous studies have also demonstrated that MSCs promoted the proliferation and angiogenic potential of ECs. ${ }^{24,25}$ Meanwhile, ECs could also facilitate the osteogenic differentiation of MSCs by release of the growth factors. ${ }^{26,27}$ It was also reported that ECs stimulated human osteoprogenitor cells differentiation through a specific gap junction connexin 43 in direct contact. $^{28}$ Therefore, the direct contact or the soluble factors secreted by HUVECs organized into vascular-like networks might accelerate the osteogenesis of hMSCs in cell sheets.

Engineered prevascularized 3D constructs using prevascularized MSC-EC composite cell sheets by stacking several cell sheets together or combined with biomaterial scaffold is a promising strategy in bone regeneration. In contrast to the addition of suspension of ECs to MSC cell sheet, the co-cultured composite cell sheet could generate more stable and pronounced 3D vascular-like network in vitro. Meanwhile, the prevascularized network would stimulate a rapid and effective anastomosis to the host vasculature in the early transplanted period. ${ }^{29}$ Further researches will be carried out to investigate the vascularization and bone formation effect of the prevascularized composite cell sheet in vivo.

In summary, we demonstrated a strategy of engineering a transferable prevascularized MSC-EC composite cell sheet to promote the vascular-like network formation for bone tissue engineering by using a light-induced cell sheet technology. Immunofluorescence elucidated that variety of vessel like structures could form under various culture conditions, such as cell ratio and media. It was found that $\mathrm{L}-\mathrm{V}$-osteo medium facilitated the robust formation of vascular-like network, especially in the cell ratio of 50/50. Furthermore, we demonstrated that cell ratio 50/50 of $\mathrm{MSC} / \mathrm{EC}$ was the optimal condition for proliferation and osteogenic differentiation of composite cell sheet, based on cell metabolic activity and ALP activity assay results. In addition, the prevascularized composite cell sheet could be detached as an intact and confluent cell layer that appeared 3D network formation surrounded by mesenchymal stem cells. The prevascularized MSC-EC composite cell sheets can be engineered into 3D construct through multiple layers stacking or combined with scaffold, indicating its great potential in further bone regeneration.

\section{Conflict of interest}

The authors declare that they have no conflict of interest.

\section{Acknowledgements}

This work was supported by National Natural Science Foundation of China [grant numbers 81600838, 81670972, 81371120,
81501607, 51502262, 51472216, 51372217, 51475419]; Medical Technology and Education of Zhejiang Province of China [grant number 2016KYB178], Research Science and Technology Department of Zhejiang Province social welfare development projects [grant number 2013C33161].

\section{References}

1 S. F. Badylak and T. W. Gilbert, Semin. Immunol., 2008, 20, 109-116.

2 N. C. Rivron, J. J. Liu, J. Rouwkema, J. de Boer and C. A. van Blitterswijk, Eur. Cells Mater., 2008, 15, 27-40.

3 X. F. Chen, A. S. Aledia, C. M. Ghajar, C. K. Griffith, A. J. Putnam, C. C. W. Hughes and S. C. George, Tissue Eng., Part A, 2009, 15, 1363-1371.

4 H. Sekine, T. Shimizu, K. Sakaguchi, I. Dobashi, M. Wada, M. Yamato, E. Kobayashi, M. Umezu and T. Okano, Nat. Commun., 2013, 4, 1399.

5 K. Matsuura, R. Utoh, K. Nagase and T. Okano, J. Controlled Release, 2014, 190, 228-239.

6 C. M. Nelson and M. J. Bissell, Annu. Rev. Cell Dev. Biol., 2006, 22, 287-309.

7 T. Shimizu, M. Yamato, A. Kikuchi and T. Okano, Biomaterials, 2003, 24, 2309-2316.

8 K. Nishida, M. Yamato, Y. Hayashida, K. Watanabe, K. Yamamoto, E. Adachi, S. Nagai, A. Kikuchi, N. Maeda, H. Watanabe, T. Okano and Y. Tano, N. Engl. J. Med., 2004, 351, 1187-1196.

9 Y. Zhou, Y. Li, L. Mao and H. Peng, Arch. Oral Biol., 2012, 57, 169-176.

10 T. Sasagawa, T. Shimizu, S. Sekiya, M. Yamato and T. Okano, J. Biomed. Mater. Res., Part A, 2014, 102, 358-365.

11 R. P. Pirraco, T. Iwata, T. Yoshida, A. P. Marques, M. Yamato, R. L. Reis and T. Okano, Lab. Invest., 2014, 94, 663-673.

12 Y. Hong, M. Yu, W. Weng, K. Cheng, H. Wang and J. Lin, Biomaterials, 2013, 34, 11-18.

13 H. Wang, Y. Zhou, D. Yu and H. Zhu, Cytotechnology, 2016, 68, 839-848.

14 L. Dong, K. Cheng, W. Weng, C. Song, P. Du, G. Shen and G. Han, Thin Solid Films, 2011, 519, 4634-4640.

15 K. Cheng, Y. Sun, H. Wan, X. Wang, W. Weng, J. Lin and H. Wang, Acta Biomater., 2015, 26, 347-354.

16 A. Das and E. Botchwey, Tissue Eng., Part B, 2011, 17, 403414.

17 J. Zhou, H. Lin, T. Fang, X. Li, W. Dai, T. Uemura and J. Dong, Biomaterials, 2010, 31, 1171-1179.

18 J. Rouwkema, J. de Boer and C. A. Van Blitterswijk, Tissue Eng., 2006, 12, 2685-2693.

19 Y. Xue, Z. Xing, S. Hellem, K. Arvidson and K. Mustafa, BioMedical Engineering Online, 2009, 8, 34.

20 S. J. Bidarra, C. C. Barrias, M. A. Barbosa, R. Soares, J. Amedee and P. L. Granja, Stem Cell Res., 2011, 7, 186-197.

21 D. Steiner, F. Lampert, G. B. Stark and G. Finkenzeller, J. Orthop. Res., 2012, 30, 1682-1689.

22 D. A. Stevens and G. R. Williams, Mol. Cell. Endocrinol., 1999, 151, 195-204. 
23 J. M. Kanczler and R. O. Oreffo, Eur. Cells Mater., 2008, 15, 100-114.

24 J. Rehman, D. Traktuev, J. Li, S. Merfeld-Clauss, C. J. TemmGrove, J. E. Bovenkerk, C. L. Pell, B. H. Johnstone, R. V. Considine and K. L. March, Circulation, 2004, 109, 1292-1298.

25 T. O. Pedersen, A. L. Blois, Y. Xue, Z. Xing, Y. Sun, A. FinneWistrand, J. B. Lorens, I. Fristad, K. N. Leknes and K. Mustafa, Stem Cell Res. Ther., 2014, 5, 23.

26 J. Wang, Y. P. Ye, H. T. Tian, S. H. Yang, X. Jin, W. Tong and Y. K. Zhang, Biochem. Biophys. Res. Commun., 2011, 412, 143149.
27 Y. Q. Kang, S. Kim, M. Fahrenholtz, A. Khademhosseini and Y. Z. Yang, Acta Biomater., 2013, 9, 4906-4915.

28 B. Guillotin, C. Bourget, M. Remy-Zolgadri, R. Bareille, P. Fernandez, V. Conrad and J. Amedee-Vilamitjana, Cellular physiology and biochemistry : international journal of experimental cellular physiology, biochemistry, and pharmacology, 2004, vol. 14, pp. 325-332.

29 L. Ren, Y. Kang, C. Browne, J. Bishop and Y. Yang, Bone, 2014, 64, 173-182. 